\section{Ramifying phylum}

The Biology of the Mollusca. By R. D. Purchon. (Second edition.) $\mathrm{Pp} x x v+$ 560. (Pergamon: Oxford and New York, 1977.) £17.50.

ARISING from a common stock with the segmented annelids and arthropods, the molluscs proceeded to evolve along totally different lines, to attain in the cephalopods the culmination of invertebrate organisation. They did so from a basis of possibly secondary simplicity-this depending on whether or not the enigmatic Neopilina may be regarded as segmented.

Contemplation of the structure of early fishes might have led some contemporary evolutionist to predict developments in structural pattern that could lead to amphibious and eventually terrestrial success. Similar survey of the first obscurely crawling molluscs could have afforded no faintest indication of possibilities eventually realised in the torsionally produced gastropods, compressed and insinuating bivalves, and predacious, rapidly darting squids.

The consequences of the radiating evolutionary possibilities of primitive molluscan structure are admirably revealed in this second edition of a book which received all too little notice when first published in 1968 .

Although a sizeable volume it cannot hope to cover the enormous extent of form, function and enviromental

\section{Fusion research}

Nuclear Fusion. Special Supplement, 1976. (World Survey of Major Facilities in Controlled Fusion Research.) Pp. 866. (International Atomic Energy Agency, Vienna, 1976.) \$48.

THIS large volume provides a unique insight into the magnitude and variety of the world's research and development effort in nuclear fusion. Following the false dawn at the time of the early Greneva Conferences, an immense amount of experimental and theoretical work by the plasma physicists has led to the construction of numerous plasma-confining devices, quite apart from more recent initiatives on the entirely distinct concept of laserimplosion devices. Now several laboratories, notably Argonne and Oak Ridge in the United States have embarked on long-range (20 years plus) development programmes of operating fusion reactors on the basis of the tokamak confinement principle, incorporating detailed development programmes in all the subsidiary technologies from ultrahigh power electrical supplies to tritium processing. specialisation achieved by members of this intricately ramifying phylum, with convergence running wild to produce both snail-like bivalves and bivalve gastropods. The author has concentrated on groups or aspects with which he is most at home or which he feels are of greatest significance.

Almost complete adherence to the original pagination has prevented any extensive introduction of new material. Due note has, however, been taken of the recent work of Professor J. A. Allen on the Verticordiidae. These latter bring the septibranch bivalves into unquestioned association with the eulamellibranchs and exclude previous ideas about possible direct connection with the protobranchs.

The precise nature and course of the digestive processes in the bivalves continues to provoke investigation. Here, Professor Purchon provides a judicious review of the present state of the controversy, largely stimulated by the work of Dr Brian Morton, on the precise cyclic nature of these processes. He has also brought up to date his sections on the distribution, and mode of spreading, of gastropods on Pacific islands.

This new edition provides an admirable introduction to the advanced study of this significant phylum.

C. M. Yonge

Sir Maurice Yonge is Honorary Fellow in Zoology at the University of Edinburgh, $U K$.

The World Survey first classifies programmes by country and laboratory; each entry specifies purpose, key personnel, main features, major results and future plans. Numerous perspective drawings of actual or conceptual reactor designs are included, the Americans, Russians, Japanese and Germans seeming to have the largest and most varied programmes. There follows a summary section classified by types of programme (confinement systems, plasma physics, heating techniques and fuel injection strategies, reactor considerations including materials research, and laser researchincluding laser-aided fuel injection into plasmas). There is an alphabetical index of more than 3,000 key scientific workers.

It is a major achievement to have assembled so much solid information in standardised format from so many sources. The scale and scope of the work described implies the growing optimism that nuclear fusion represents a genuine hope as an energy source for the twenty-first century.

Robert W. Cahn

Robert W. Cahn is Professor of Materials Science at the University of Sussex, UK.
The May issue of Nucleic Acids Research is devoted to papers written by former colleagues and friends of Jerome Vinograd (1913-1976). This memorial issue is respectfully dedicated to him.

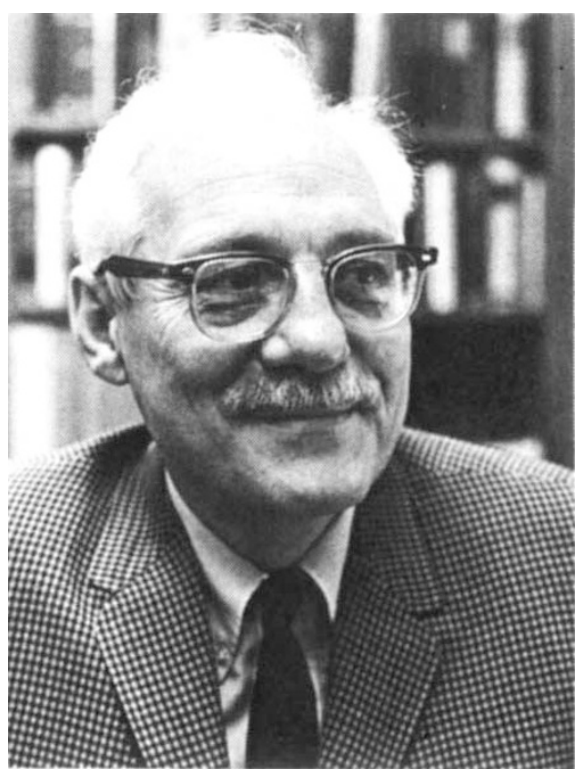

Information Retrieval Limited 1 Falconberg Court London W1V 5FG

\section{Information Retrieval Inc 1911 Jefferson Davis Highway - Arlington Virginia 22202 USA}

